\title{
Contribution of breast density to the volume of the augmented breast: A preliminary study
}

\author{
Sean M Hill MD, Franziska Huettner MD PhD, John Murray MD, Eric Elwood MD, Rebecca Barrick PA, Glyn Jones MD
}

\begin{abstract}
SM Hill, F Huettner, J Murray, E Elwood, R Barrick, G Jones. Contribution of breast density to the volume of the augmented breast: A preliminary study. Can J Plast Surg 2011;19(3):93-96.
\end{abstract}

BACKGROUND: Prediction of soft tissue contribution to the shape, volume and texture of the augmented breast proves to be an ever-challenging, uncontrollable variable. Similarly, the understanding of the contribution of breast density in breast augmentation has been elusive and, generally, not well studied.

OBJECTIVE: With the aid of three-dimensional photographic analysis, the present preliminary study examined the contribution of differing breast densities to the overall volume of the augmented breast.

METHODS: All patients undergoing primary augmentation over a six-month period were included in the study. To standardize technique and implant type, all patients received saline-filled moderate-profile implants, which were placed partially underneath the pectoralis muscle through a lower pole approach. Photographic analysis of the breast volume was completed preoperatively and, subsequently, at a minimum of six months postoperatively. Preoperatively, each breast was also assigned to one of four classes of increasing mammographic density, as judged by the mammographic radiologist (fatty, moderately dense, heterogeneously dense and extremely dense). Postoperative breast volumes were, subsequently, correlated to mammographic densities.

RESULTS: Thirty-eight augmented breasts in 21 patients were examined. The average volume gain based on the implant size used was $92.7 \%$. Heterogeneously dense breasts comprised $68 \%$ of the total breasts and showed an average volume gain of $100.67 \%$, extremely dense breasts comprised $26 \%$ of the total breasts and showed an average volume gain of $97.3 \%$, and moderately dense breasts comprised $5 \%$ of the total breasts with an average gain of $100.04 \%$. There was no significant difference between the augmented breast volumes and the respective expected volumes (combined preaugmented breast volumes and implant volumes; $\mathrm{P}=0.3483$ ). Additionally, no statistical difference was found between the density classes and the expected augmented volumes.

CONCLUSION: No statistical difference was found between expected and actual augmented breast volumes among or between four different breast density classes. Thus, one would expect that the soft tissue compression or the response of the impression of the implant on the parenchyma, would not be statistically different among classes. Additionally, compressive atrophy, as seen with atrophy of the breasts over time, would be expected to be multifactorial and not uniquely independent to breast density. However, longitudinal analysis is needed to study the durability of breast shape relative to breast density.

Key Words: Breast; Breast augmentation; Breast density; Breast implant; Breast implant size; Mammographic density

$\mathrm{B}$ reast reconstruction and augmentation plays an important role in the field of plastic surgery. The procedure can help a woman feel complete, and can re-establish her emotional balance and self-esteem after suffering through a horrifying battle. Breast augmentation is one of the five most common procedures performed by plastic surgeons (1). Women undergo this procedure for mainly two reasons: bilateral hypoplasia of the breast or asymmetry of the breasts due to breast reconstruction

\section{L'apport de la densité mammaire au volume des seins augmentés : une étude préliminaire}

HISTORIQUE : La prédiction de l'apport des tissus mous à la forme, au volume et à la texture des seins augmentés constitue une variable incontrôlable toujours difficile à évaluer. De même, il est difficile de comprendre l'apport de la densité mammaire à l'augmentation du volume des seins et, en général, ce phénomène a mal été étudié.

OBJECTIF : À l'aide d'une analyse photographique tridimensionnelle, la présente étude préliminaire a permis d'examiner l'apport des diverses densités mammaires au volume global des seins augmentés.

MÉTHODOLOGIE : Toutes les patientes qui ont subi une augmentation primaire pendant une période de six mois ont participé à l'étude. Pour standardiser la technique et le type d'implant, toutes les patientes ont reçu des implants remplis de solution saline à profil modéré, partiellement placés sous le muscle pectoral au moyen d'une approche par pôle inférieur. Les chercheurs ont terminé l'analyse photographique du volume mammaire avant l'opération, puis au plus tôt six mois après l'opération. Avant l'opération, chaque sein se voyait attribuer l'une des quatre catégories croissantes de densité mammographique, selon l'évaluation d'un radiologiste mammographique (gras, densité modérée, densité hétérogène et densité extrême). Les volumes des seins après l'opération ont ensuite été corrélés aux densités mammographiques.

RÉSULTATS : Les chercheurs ont examiné 38 seins augmentés chez 21 patientes. L'augmentation du volume moyen sur la dimension de l'implant utilisé était de $92,7 \%$. Les seins à la densité hétérogène représentaient $68 \%$ des seins totaux et présentaient un gain moyen de volume de 100,67 \%, les seins à la densité extrême représentaient $26 \%$ des seins totaux et présentaient un gain de volume moyen de 97,3\% et les seins à la densité modérée représentaient $5 \%$ des seins totaux, et présentaient un grain moyen de volume de 100,04 \%. Les chercheurs n'ont constaté aucune différence significative entre le volume des seins augmentés et le volume respectif prévu (volume combiné des seins avant l'augmentation et volume des implants; $\mathrm{P}=0,3483)$. De plus, ils n'ont remarqué aucune différence statistique entre les catégories de densité et le volume d'augmentation prévu.

CONCLUSION : Les chercheurs n'ont découvert aucune différence statistique entre le volume prévu et réel des seins augmentés entre quatre catégories de densité mammaire. Ainsi, on penserait que la compression des tissus mous ou l'impression de l'implant sur le parenchyme n'est pas statistiquement significative entre les catégories. De plus, on s'attendrait que l'atrophie compressive observée par l'atrophie des seins au fil du temps soit multifactorielle et ne dépende pas seulement de la densité mammaire. Cependant, il faudrait une analyse longitudinale pour étudier la durabilité de la forme des seins par rapport à leur densité.

of the contralateral side as a consequence of cancer surgery. In both situations, it is most important to try to meet the patient's expectations and to create two symmetrical breasts. In previous years, breast reconstruction and augmentation has relied on the surgeon's subjective appreciation of breast tissue characteristics matched with technique and knowledge of wound healing to achieve an aesthetically pleasing result. Currently, three-dimensional digital analysis offers the ability to 


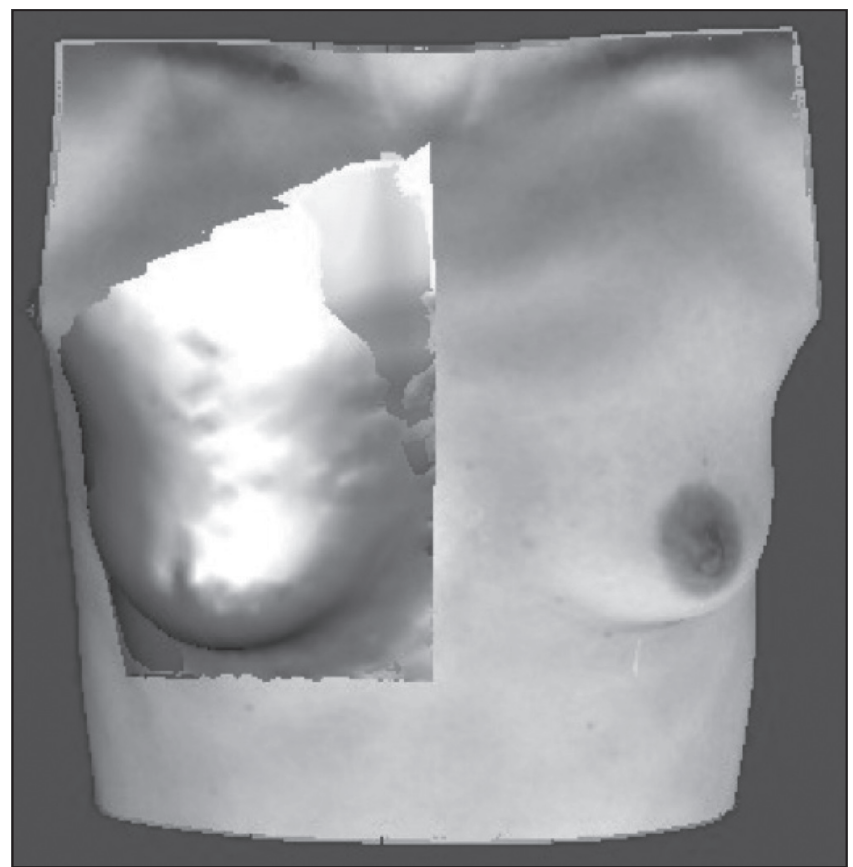

Figure 1) Preoperative breast image with $3 \mathrm{dMDtorso}$ ( $3 \mathrm{dMD}$, USA) reconstruction. The outlined area represents the Coons patch used to calculate volume. The four corners represent the sternal notch, crossing of the anterior axillary line and pectoralis muscle, crossing of the anterior axillary line and horizontal line beneath the breast, and crossing of the midline torso and horizontal line beneath the breast

objectively define anatomical subtleties to refine surgical technique through its capacity to calculate breast volume, surface area, shape, size and contour (2).

Baseline volume data can be objectively collected before deciding on the correct implant size to match the cancer-free breast. To improve the outcome of breast augmentation, factors such as patient age and breast density on mammogram must be evaluated. The purpose of the present study was to objectively measure the truly created breast volume (using three-dimensional photography) and compare it with the implant size used for augmentation; furthermore, the study compared the results with breast density on mammogram. The resulting volume and the actual implant size used for augmentation were subsequently compared with breast density on mammogram. The hypothesis was that a younger, more dense breast results in compression of the breast implant and, therefore, leads to smaller true breast volumes when compared with the implant size.

\section{PATIENTS AND METHODS}

The present institutional review board-approved retrospective study describes the use of three-dimensional photography (3dMDtorso, $3 \mathrm{dMD}, \mathrm{USA}$ ) for analysis of the augmented breast.

The $3 \mathrm{dMDtorso}$ system is a 12 -camera system that is based on the principles of stereophotogrammetry to be able to capture the patient's image in $1.5 \mathrm{~ms}$ and to generate a highly precise, digital threedimensional model of the human anatomy (Figures 1 and 2).

A series of patients at the Illinois Plastic Surgery Center (USA) who had undergone breast augmentation over a six-month period for either bilateral hypoplasia or unilateral augmentation for symmetry were chosen. Twenty-one patients representing a total number of 38 breasts were evaluated. Augmentation for breast hypoplasia was performed in 17 cases, and for symmetry reasons in four cases. Preoperative, informed patient consents for the procedure and photography were obtained. To qualify for the study, the patients needed to have had a three-dimensional photograph taken both before and at a minimum of six months postoperatively using the $3 \mathrm{dMD}$ technology.

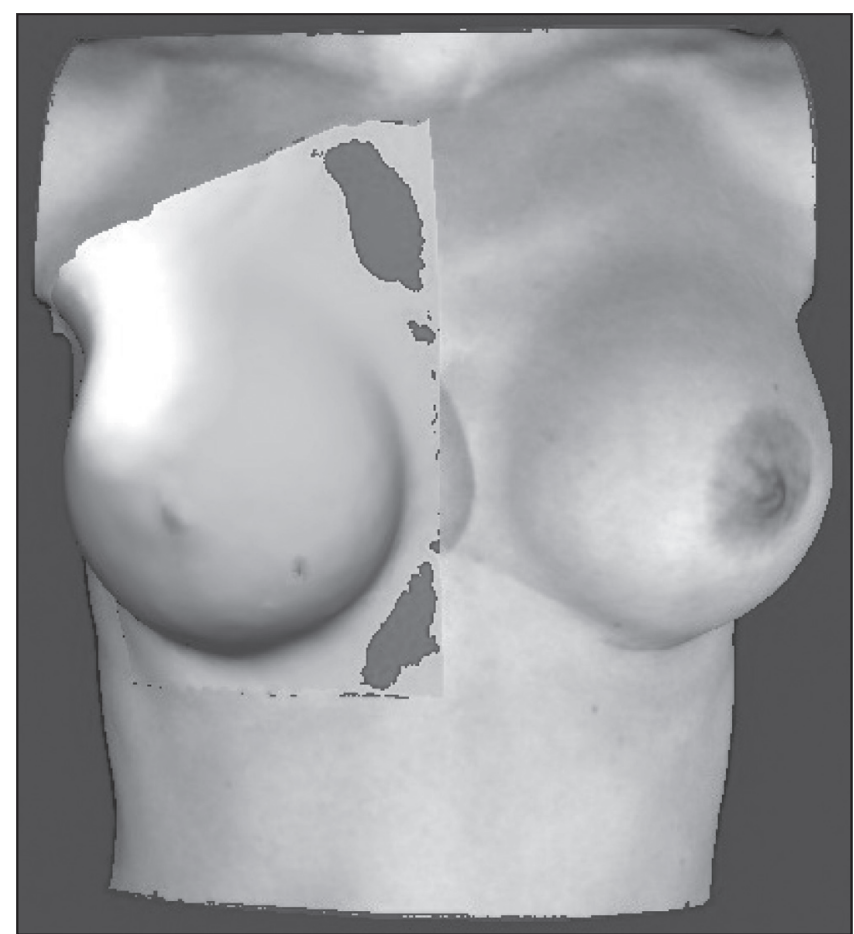

Figure 2) Postoperative breast image with $3 \mathrm{dMD}$ torso (3dMD, USA) reconstruction. The outlined area represents the Coons patch used to calculate volume. The four corners represent the sternal notch, crossing of the anterior axillary line and pectoralis muscle, crossing of the anterior axillary line and horizontal line beneath the breast, and crossing of the midline torso and horizontal line beneath the breast

The breast volumes were measured pre- and postoperatively using a Coons patch.

Four different points on the patients' torsos were chosen for calculation purposes, and these same points were used in every patient: sternal notch, crossing of the anterior axillary line and pectoralis muscle, crossing of the anterior axillary line and horizontal line beneath the breast, and crossing of the midline torso and horizontal line beneath the breast (Figure 1). The 3dMDtorso system calculated the volume of the breast. The authors were unable to place the point at the exact same pixel on the screen; therefore, the error in measurement was accounted for by calculating the mean of three measurements per breast. Pre- and postoperative volumes were compared and the difference was calculated. The calculated volume difference was converted to percentage of volume gain, relative to the implant size, which was $100 \%$. The results were compared with breast density obtained by mammogram.

Statistical analysis was performed using a paired $t$ test (Graphed Quick Cals, Graphed Software Inc, USA).

\section{RESULTS}

Thirty-eight breasts of 21 women (average age 38.2 years [range 19 to 58 years]) were transformed into three-dimensional images. The mean implant size used was $305.79 \mathrm{~mL}$. The mean volume difference measured was $282.96 \mathrm{~mL}$. The mean volume gain was $92.7 \%$ (range $58.7 \%$ to $130.2 \%$ ) (Table 1 ).

With regard to breast density on the mammogram, all breasts were classified as dense. Heterogeneously dense breasts comprised 68\% of the total breasts and showed an average volume gain of $100.67 \%$, extremely dense breasts comprised $26 \%$ of the total breasts and showed an average volume gain of $97.3 \%$, and moderately dense breasts comprised $5 \%$ of the total breasts with an average gain of $100.04 \%$.

There was no significant difference between the augmented breast volumes and the respective expected volumes (combined preaugmented 
TABLE 1

Preoperative (preop) and postoperative (postop) breast volume, volume gained and the volume of breast implant used

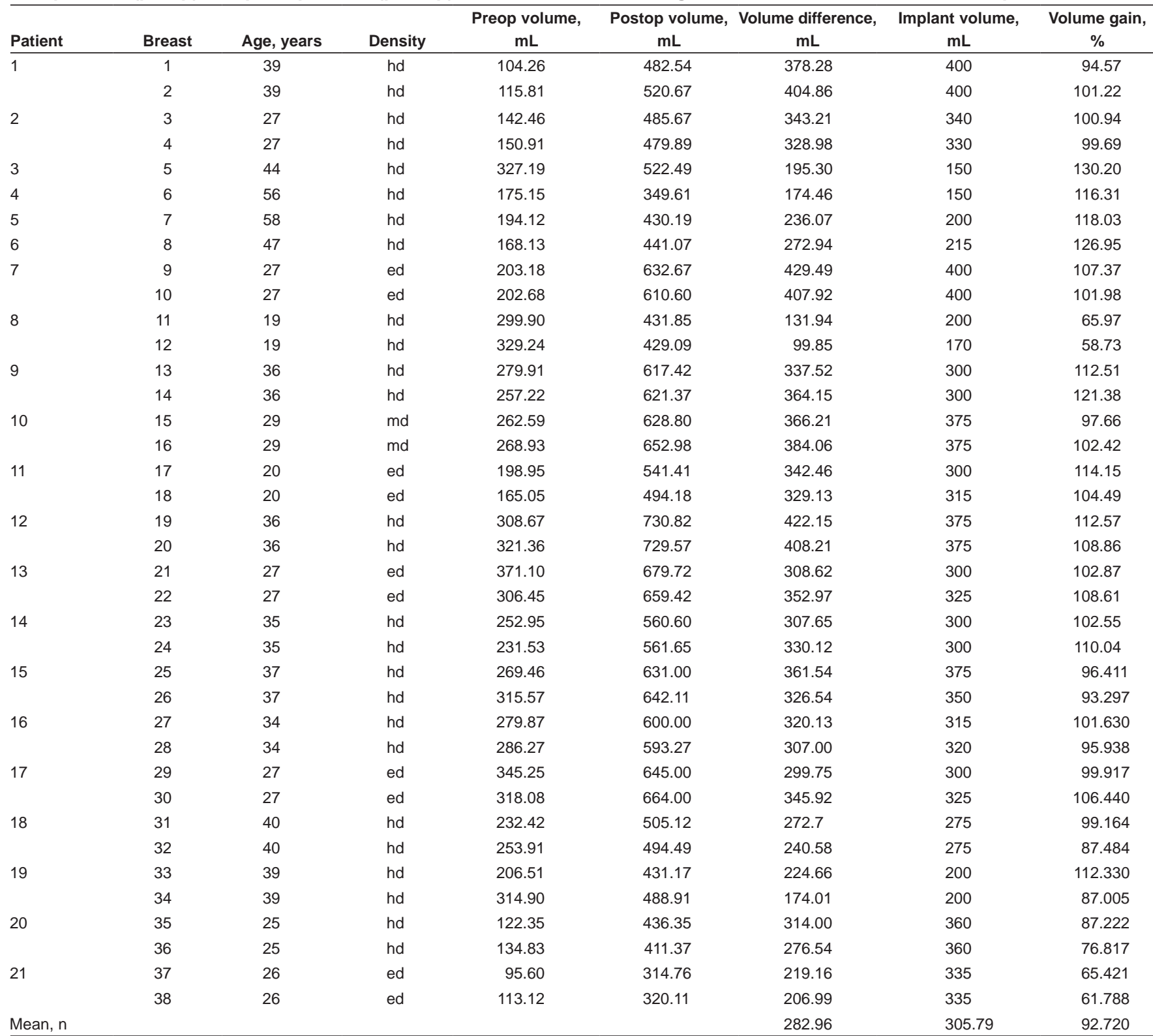

'Volume gain, \%' is a measurement of the postop volume observed divided by volume expected and multiplied by 100 to convert to a percentage. Density represents the observed mammographic density. ed Extremely dense; hd Heterogeneously dense; md Moderately dense

breast volumes and implant volumes) $(\mathrm{P}=0.3483)$. No statistical difference was found between the density classes and the expected augmented volumes.

\section{DISCUSSION}

Breast augmentation is one of the most commonly performed procedures in the field of plastic surgery, with the breast being the universal symbol of femininity and sexuality. Obtaining symmetrical breast size and the proper postoperative volume for the patient is of the upmost importance in breast surgery. However, no universally accepted method for calculating breast volumes exists.

Determining the volume and implant size needed for unilateral augmentation after breast reconstruction of the contralateral side or the most aesthetically pleasing volume in bilateral augmentation is critical. Tebbets (3) proposed his TEPID system to evaluate individual tissue characteristics to determine the size of implant that would give the most aesthetically pleasing breast. This system addresses the tissue characteristics $(\mathrm{T})$ of the envelope $(\mathrm{E})$, the parenchyma $(\mathrm{P})$, and the implant (I), and the dynamics (D) of the implant and filler distribution that affects the soft tissue (3). This system was revised in 2005 with the high five support process, which allowed all preoperative planning to be accomplished in $5 \mathrm{~min}$ (4). The first decision is optimal soft tissue coverage/ pocket location of the implant, which eliminates future risk of rippling, and visible or palpable edges. Second is the implant volume, which takes into account the effect on the tissue over time, resulting in rippling or ptosis over time. Third is the implant size, type and dimensions, which control the distribution of the implant within the breast. Fourth is consideration for the optimal location of the inframammary fold, which is based on the width of the implant chosen for augmentation. This dimension is critical to the aesthetic relationship between the 
breast width and nipple-to-fold distance, and distribution of fill. Finally, the fifth decision is incision location. Using this system, Tebbets and Adams (4) reported a reoperation rate of 3\% at seven-year follow-up.

The evaluation of reoperative breast volume up to this point was subjective or dependent on two-dimensional photographs, photographic stereograms (such as magnetic resonance imaging [MRI], computed tomography and ultrasound) or traditional anthropomorphic measurements (5) (such as the Archimedean water displacement method [6], plaster molds and mammograms). These methods are all limited in evaluating the shape, volume and symmetry of the breast.

In contrast, three-dimensional imaging provides a better spatial understanding of anatomical structures to be treated, which can lead to improvement in planning treatment and surgical approach. The $3 \mathrm{dMD}$ system has been shown to produce consistent, reproducible, observer-independent, accurate results (7) without exposing the patient to radiation (2). It is also minimally invasive, fast and practical, and causes no breast deformity or pain to the patient. Threedimensional imaging is currently being used for objective evaluation of breast asymmetry (7) because of its ability to quantify breast size and shape, surface area, volume, contour and surface measurement. It is a technology that is revolutionizing the way we plan and document procedures, and can possibly lead to an improvement for better communication.

The accuracy of three-dimensional surface imaging was tested by Kovacs et al (8) in 2006 when they compared the precision and accuracy of three-dimensional scanning with MRI (8). Five independent observers measured the volume of six test subjects using a threedimensional scanning system, and these volumes were compared with those using MRI. It was found that the volume obtained using three-dimensional surface imaging correlated with MRI measurements. An additional study by Kovacs et al (9) in 2007 compared three-dimensional scanning with other classical methods to assess volume. Repeated breast volume measurement was performed using a

\section{REFERENCES}

1. Rohrich RJ. The increasing popularity of cosmetic surgery procedures: A look at statistics in plastic surgery. Plast Reconstr Surg 2000;106:1363-5.

2. Nahabedian MY, Galdino G. Symmetrical breast reconstruction: Is there a role for three-dimensional digital photography? Plast Reconstr Surg 2003;112:1582-90.

3. Tebbets JB. A system for breast implant selection based on patient tissue characteristics and implant - soft tissue dynamics. Plast Reconstr Surg 2002;109:1396-409.

4. Tebbets JB, Adams WP. Five critical decisions in breast augmentation using five measurements in 5 minutes: The high five decision support process. Plast Reconstr Surg 2005;116:2005-16.

5. Wesreich M. Anthropomorphic breast measurement: Protocol and results in 50 women with aesthetically perfect breasts and clinical application. Plast Reconstr Surg 1997;100:468-79. three-dimensional laser scanner, nuclear MRI, thermoplastic castings and anthropomorphic measurements. When comparing these volumes, it was found that three-dimensional scanning measurement showed the best agreement with MRI compared with the others (9). These studies further validate this method as a quick, cost-effective and accurate alternative to MRI in volume assessment for breast surgery.

The technical feasibility and clinical utility of three-dimensional geometric data were demonstrated by Tepper et al (10) by obtaining three-dimensional scans for patients undergoing short-scar medial pedicle breast reduction. Both pre- and postoperative threedimensional models were obtained for 30 patients. These models demonstrated that a significant change in tissue percentage was located above the inframammary fold postoperatively (76\%) compared with preoperatively (45\%) (10).

Overall, three-dimensional photography is safe (no exposure to radiation), simple (12 cameras taking one picture simultaneously), convenient (no special room necessary), easy (can be operated by clinical staff) and noninvasive; it can truly become a valuable instrument in breast surgery procedures. Additional studies are necessary to assess its value in both reconstructive and aesthetic breast surgery; however, early results are promising.

\section{CONCLUSION}

No statistical difference was found between expected and actual augmented breast volumes among or between four different breast density classes. Thus, one would expect that the soft tissue compression or the response of the impression of the implant on the parenchyma would not be statistically different among classes. Additionally, compressive atrophy, as seen with atrophy of the breasts over time, would be expected to be multifactorial and not uniquely independent to breast density. However, longitudinal analysis will be needed to study the durability of breast shape relative to breast density.
6. Tezel E, Numanoglu A. Practical do-it-yourself device for accurate volume measurement of breast. Plast Reconstr Surg 2000;105:1019-23.

7. Losken A, Seify H, Denson DD, Paredes AA, Carlson G. Validating three-dimensional imaging of the breast. Ann Plast Surg 2005;54;471-6.

8. Kovacs L, Eder M, Hollweck R, et al. New aspects of breast volume measurement using 3-dimensional surface imaging. Ann Plast Surg 2006;57:602-10.

9. Kovacs L, Eder M, Hollweck R, et al. Comparison between breast volume measurement using 3D surface imaging and classical techniques. Breast 2007;16:137-45.

10. Tepper OM, Choi M, Small K, et al. An innovative three-dimensional approach to defining the anatomical changes occurring after short scar-medial pedicle reduction mammaplasty. Plast Reconstr Surg 2008;121:1875-85. 